\title{
The Importance of Soft Skills Development to Enhance Entrepreneurial Capacity
}

\author{
Sarom Tem ${ }^{1}$, Ariyabhorn Kuroda ${ }^{1} \&$ Keow Ngang Tang ${ }^{2}$ \\ ${ }^{1}$ Faculty of Education, Khon Kaen University, Khon Kaen 40002, Thailand \\ ${ }^{2}$ Institute for Research and Development in Teaching Profession for ASEAN, Khon Kaen University, Thailand \\ Correspondence: Keow Ngang Tang, Institute for Research and Development in Teaching Profession for ASEAN,

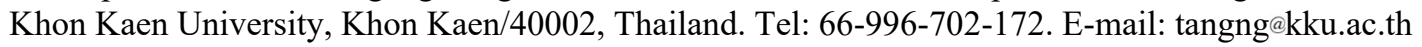

Received: July 12, 2020; Accepted: July 25, 2020; Published: July 28, 2020

The research is supported by the Faculty of Education, Khon Kaen University, Khon Kaen 40002, Thailand.

\begin{abstract}
Soft skills development has come with the intention of an all-rounded development of individual personality and entrepreneurship can be taught or not has been an argument until today. Therefore, this study was designed to explore the importance of soft skills to enhance entrepreneurial capacity. The three key soft skills that researchers examined were communication, leadership, and critical and problem-solving skills while the entrepreneurial capacity was the dependent variable of this study. A total of five successful entrepreneurs were purposively selected to be the informants of this study. Researchers employed a qualitative method using interview protocol as an instrument to conduct in-depth interviews. Data were analyzed using content analysis. The results revealed that critical thinking and problem-solving skills is the most significant soft skills to assist entrepreneurs to improve their competitiveness and productivity. Moreover, all the informants came to the consensus that higher education should teach the students the three required soft skills to be successful entrepreneurs. They emphasized the importance of soft skills that can assist entrepreneurs not only to compete in the formal labor market but also has the potential to reduce youth unemployment, drive economic growth, and reduce poverty. The overall results are successfully contributed to a growing body of research by suggesting that soft skills, namely communication, leadership, and critical thinking and problem-solving skills associated with entrepreneurial success are malleable and can be trained through higher education institutions.
\end{abstract}

Keywords: communication, critical thinking and problem-solving, entrepreneurial capacity, leadership, soft skills development

\section{Introduction}

Soft skills refer to all aspects of generic skills that include both cognitive elements and non-academic skills. Hence, soft skills are identified to be the most critical skills in the current global job market particularly in the area of entrepreneurship which is in a rapidly moving era of technology (Jain, 2009). On the other hand, entrepreneurship can be considered a fragment of the current strategy to boost the economy. This is because entrepreneurship can undertake those challenging tasks, within the organization either internally or externally by the creation of new businesses that are sustainable not only in a specific market but also in a complex economic environment (Josẽ Sousa \& Do Rosặrio Almeida, 2014).

According to Tang (2019a), soft skills such as leadership, communication, and critical thinking and problemsolving skills should be embedded in the course contents of higher education to enhance graduate employability. Besides, Chamorro-Premuzic et al. (2010) emphasized the importance of soft skills that including the abilities to collaborate, communicate, and problem-solving in higher education training over the past decade. Past researchers (Tan \& Tang, 2015; Tang, 2018; Tang, 2019a; Tang 2019b; Tang, Mohamed, Somprach, 2015a; Tang, Tan, \& Vetriveilmany, 2015b) found that there are three important soft skills namely leadership, critical thinking and problem-solving, and communication skills needed for higher education students who are studying in business studies programs either in diploma or bachelor degree. They concluded that future entrepreneurs need these three soft skills more than other soft skills to assist them in dealing with business activities and being more competitive. 
Leadership skill in this study refers to an entrepreneur gives his or her subordinates the authority and support to make decisions, properly uses and personalizes recognition and incentives to reward, sets a personal example, shows consistently and maintains high standards of integrity and ethical conduct during both good and tough times, learns from experience, gain intuitions from mistakes, and analyzes both successes and failures for pieces of evidence to improvement (Tang et al., 2015a). The biggest variables in a workplace are subordinates who are possessing complex needs, strengths, weaknesses, biases, and not to mention, fears. Therefore, organizational leaders need to help subordinates communicate, find meaning in their work, and work in cooperation with each other at a higher level. Synergized workplace elements of the leader include his or her ability to communicate, get along with different people, work as a team, infuse creativity, create an environment where people feel valued, and become eager to contribute to the organization (Tang, 2012).

Communication skill refers to job communication that covers being self-reliant about communication to individuals either over the phone or face-to-face as well as clarity of emails and memos writing to make readers understand (Holmes, 2014). For instance, writing proposals and reports, blogging, or using social media, and making the verbal presentation. Therefore, good communication skill in this study means the capacity to communicate with a wide variety of people both verbally and in writing, display a wide-ranging vocabulary, maintain good eye contact, write clearly and concisely, and adapt our language to our customers are all essential skills that entrepreneurs should possess. In other words, good verbal and written communication means entrepreneurs can acquire their messages across with less unintentional errors. (Tang, 2019a).

On the other hand, critical thinking and problem-solving skills are defined as the ability to solve the problem and make a proper decision. Critical thinking refers to an entrepreneur's ability to understand, assess, and assume information, and draw conclusions. Moreover, decision making and problem-solving require accumulating reliable information, evaluating the information for a variety of resolutions, and choosing the best choice based on the standards and situation. An entrepreneur who possesses this soft skill will be able to evaluate business situations and solve most of the problems in his or her job tasks. Nevertheless, entrepreneur with this skill should be logical and make a coherent decision, plan, and organize his or her subordinates effectively, and are probable to get the job tasks completed appropriately for the first time. Although the ability to solve problems and make appropriate choices is sometimes critical it is useful for entrepreneurs because they can save money and time (Tang, 2019a).

Entrepreneurship is defined as an individual or collective system of the organizational structure either internally or externally in developing something new, from the conception of ideas to the creation of a business (Josẽ Sousa \& Do Rosặrio Almeida, 2014). In other words, an entrepreneurial company is generally focusing on innovation, opening to risks, and proactive concerning its competitors as the concept of applied entrepreneurship (Miller \& Friesen, 1983). Thus, entrepreneurship is growing as a concept by placing the level of importance on the development and sustainability of the economy.

According to McMullen and Shepherd (2006), entrepreneurial capacity is not only the creation of an entrepreneurial culture that goes beyond the fear of risk but also the stigma of failure, that influence decisively the entrepreneurship context. Although entrepreneurs' profile is crucial to define a business idea and implement it successfully, higher education institutions must play a vital role in the creation of knowledge and skills to develop entrepreneurial capacity. Entrepreneurial capacity is comprised of four components, the capacity to innovate and be creative, capacity to identify and exploit new business opportunities, capacity and willingness to undertake risk, and capacity to create and develop business networks (Josẽ Sousa \& Do Rosặrio Almeida, 2014).

Since the last two decades, Cambodia's economic growth has been increasing to seven percent, creating a demand in the industries of hospitality, food, and beverage in response to the rising middle class as well as for domestic and international tourism (Asia Forward, July 12, 2018). Besides, Cambodia has experienced a challenging and often turbulent history that causing a heavy focus on economic transformation since 2002. In only a few years, this transformation brought "profound social and political changes" in entrepreneurship development as well (Pratt \& Yongvanit, 2018).

It is considered a global issue to the creation of a long-lasting relationship between higher education and the economy (Tang, 2019b). Therefore, the main role of higher education is to train their students by cultivating their acquaintance, skills, approaches, and abilities, and instantaneously allowing them as life-long, critical, and reflective human resources (Harvey, 2000). Undeniably, soft skills are found to be the priority in 77 percent of a recent review of 28 studies depending on employer surveys across multiple countries (Groh et al., 2016). In short, soft skills are reflected to enhance competency and to subsequently increase an individual's ability in supporting communal development and revolution (Tang, 2018). 
According to Salleh, Sulaiman, and Talib (2010), soft skills are the most operative instruments and methods for higher education institutions to appraise the future capabilities of their graduates. As a result, recognizing and evolving the importance of soft skills development has been a thought-provoking task for curriculum designers at higher educational training (Hodges \& Burchell, 2003). The above wide-ranging research including expert opinions indicates that current research must apply effort to regulate the precise soft skills acquired by future entrepreneurs who are studying in entrepreneurship program in a public university of Cambodia. Based on the proposed soft skills model from the Ministry of Education in either Thailand or Malaysia, the researchers identified three soft skills to be investigated. The studied soft skills consisted of communication, critical and problem solving, and leadership skills. In this line of reasoning, researchers interested to investigate how the importance of soft skills development to integrate into the training program of higher education to generate their graduates' entrepreneurial capacity.

\section{Method}

The exploratory research design was employed as it is regarded as the most useful in the preliminary stage of this study when there are levels of uncertainty and general ignorance of the subject (Webb, 1992). This study design allows the researchers to explore the five informants through complex interventions, relationships, entrepreneurial community, or phenomenon in which it occurred (Yin, 2003). Therefore, this study was conducted to empower young entrepreneurs to enhance youth entrepreneurship and success of youth-owned businesses by creating a platform for networking, sharing, learning, and synergizing business opportunities, thereby contributing to productive employment and economic development that build the next generation economy for Cambodia and among students who are from entrepreneurship program in a public university. Thus, the study was located at the success business owner site of private sectors and university students in Phnom Penh, Cambodia.

Researchers purposively selected those business owners from various sectors such as education, logistics, information technology, import-export, and real estate who are young entrepreneurs. The criteria for selection were the numbers of businesses that have grown steadily to about 514,000 enterprises within five years. According to Than (2015), among those establishments, female representatives account for $61 \%(313,391$ enterprises) and male representatives account for 39\% (200,369 enterprises). Hence, five informants were purposively selected not only they are the successful entrepreneurs in the five identified business areas as mentioned above but also, they were selected in proportional ratio as 3 Females: 2 Males to avoid gender bias issue.

A qualitative research technique utilizing in-depth interviewing was employed in this study. It involves conducting intensive individual interviews with a small number of informants to explore their perspectives on a particular idea of the importance of soft skills to enhance entrepreneurial capacity. In-depth interviews are appropriate in this study because researchers would like to have detailed information about these informants' thoughts to explore the soft skills issues in depth before developing a substantial soft skills development training program. According to Boyce and Neale (2006), interviews are usually used to provide context to other data such as outcome data, offering a more complete picture of what happened in the current business context and how higher education can prepare future entrepreneurs with sufficient soft skills.

Moreover, researchers themselves were the principal data collection instrument because the data from the five informants were arguments in the setting of the research problem (Holloway \& Wheeler, 2002). To pledge the reliability of the interview data, the researchers' video and audio recorded all the five informants' views and experiences along with the five interview sessions. An interview protocol was designed with the seven questions used as an instrument to collect qualitative data concerning the importance of the soft skills for being a successful entrepreneur concerning the relevant soft skills development training needed. This interview protocol was developed using Interview Protocol Refinement (IPR) Framework with a four-phase process to develop and finetune for the interview protocols. The IPR's four phases include ensuring interview questions align with the study's research questions, organizing an interview protocol to create an inquiry-based conversation, having reviewed by others, and finally piloting it.

Pilot testing was conducted by selecting three young entrepreneurs in the capital of Cambodia, Phnom Penh but they were not involved as informants in the actual study. It was determined that the instrument was valid and reliable as the panels of the pilot study showed their precise understanding and gave some feedback on the relevancy of the interview questions. Data were collected after researchers explained the aims of the study. Then the informants were required to elaborate to what extend the three soft skills, namely leadership, communication, and critical thinking and problem-solving skills need to integrate into the professional training of higher education institutions. Finally, informants would discuss on the importance of soft skills to enhance entrepreneurial capacity. Data collected from the in-depth interview were analyzed using the constant comparative method. The process of 
organizing information, synthesizing, and making sense of the information would enable the researchers to obtain in-depth information and make interpretation of the interviews.

\section{Results}

For this paper, researchers focused on qualitative data collected from interviews of five young and successful entrepreneurs who voluntarily agreed to participate in our preliminary study. They are three females and two males and labeled as R1 to R5. The five informants are from the following business areas of Information Technology, Import and Export, Business Training Center, Logistic Company, and Real Estate. All of them are members of the Young Entrepreneurs Association of Cambodia. The results from the five informants' points of view about the importance of soft skills to be successful entrepreneurs were taken into consideration.

\subsection{Importance of Soft Skills for Entrepreneurs}

The qualitative results discovered that all the informants agreed that soft skills are important for being a successful entrepreneur because soft skills enable entrepreneurs to be good leaders. Moreover, soft skills acquisition can motivate them to do a new thing, encourage them to share their ideas, can communicate effectively with their customers and business partners. On top of that, entrepreneurs with sufficient soft skills can motivate their colleagues and stakeholders to involve actively in their business activities. The related results were indicated in the following verbatim data:

"It is very important for every entrepreneur. If you do not have good soft skills, you cannot become an entrepreneur because soft skills are very important for everyone including subordinates, leaders, and entrepreneurs". (R3)

"In my opinion, I do agree that soft skill is very important for an entrepreneur in general. We can separate skills in soft skills and hard skills. Entrepreneurs cannot have only hard skills, but they should have soft skills for entrepreneurial development. If entrepreneurs have soft skills in mind, they can develop themselves as good leadership for the success of enterprise". (R4)

"I think the soft skills are very important because the soft skill is the mindset and provide entrepreneurs to keep moving forward and to be motivated to do something new and have innovative mind most of the time". (R1)

"I am sure that soft skills are important for an entrepreneur because they encourage you to share the idea, innovate new thing, and be able to connect with customers, business partners as well. From my experiences, communication is the most significant to an entrepreneur". (R2)

"Based on my idea, soft skill is very important for entrepreneurs because it involves motivation for my colleagues, the stakeholders, and other sectors that involve in the business activities". (R5)

\subsection{Comparison of the Importance of the Three Soft Skills for Entrepreneurs}

When the five informants were required to make a comparison of the importance of the three soft skills, majority of the informants revealed that critical thinking and problem-solving skill is the most important soft skill among the three soft skills. They supported their views by indicating that critical thinking and problem-solving skill enables entrepreneurs to improve their capacities in a competitiveness and productive business environment. The following are the verbatim results from the informants:

"My conception regarding critical thinking and problem-solving skill is significant because if entrepreneurs have strong ability in critical thinking and problem-solving skill, they can find alternative ways to solve the problem for their business operation". (R4)

"I think that critical thinking and problem-solving skill is very important for entrepreneurs because they can make new thing happen both creatively and innovatively". (R1)

\subsection{The Methods to Integrate Soft Skills in the Entrepreneurship Training Program}

The results from the three informants, namely R1 to R3 highlighted the importance of higher education institutions to integrate soft skills such as leadership, communication, and critical thinking and problem-solving skills in the entrepreneurial training programs to enhance their entrepreneurial capacity. These informants suggested having need assessment, observation assessment, and short course training with case study and group exercise to integrate the soft skills through the entrepreneurship training program of higher education. Additionally, they added that entrepreneurs should develop the official short course training to train their subordinates, supervisors, managers, and leaders in their business organization from time to time. The following are the verbatim results from the informants: 
"When conducting a training program, we should do need assessment, training needs assessment as well as need to design the course including the soft skills. When you identify the program and you want the entrepreneurs to learn the soft skills before design the program. I believe that you need to conduct the need assessment to investigate what they need to know and what they have already possessed". (R3)

"Yes, the entrepreneurial program should integrate some activities such as case study, group discussion and exercise into the three soft skills to ensure that students are more on the real practice in leadership, communication, critical thinking and problem-solving matters". (R1)

"Currently, I observe that soft skills of leadership, communication, critical thinking and problem-solving should be developed a short course training in the entrepreneurial program because they can ensure the enhancement of enterprise awareness, entrepreneurial mindset, and entrepreneurial capacity". (R2)

\subsection{Soft Skills Developmental Process needs to be Assessed Throughout the Training}

The soft skills developmental process is difficult to measure. In this line of reasoning, R1 and R3 detailed that the three soft skills need to be assessed by observing the progression of soft skills acquisition using a checklist as an instrument. Moreover, they pointed out that the assessment can provide meaningful feedback to the trainer to identify trainees' soft skills developmental process precisely. The following are the verbatim results from the informants:

"Yes, you know when assess the need to design the questionnaire, observation and checklist" Yes or No" like this......no need to ask the question that just observation and checklist. So it is very important that when the developmental process as you need to develop the question, checklist and then list down what you want to know and observe the entrepreneurs whoever that want to assess his or her skills after that we can provide the feedback with the real program". (R3)

"Soft skill could assess through development process somehow we have a list of items that solving capacity of entrepreneurs to be the leadership that could be somehow like checklist cooperate criteria for entrepreneurship in terms of leadership, communication skill and also critical thinking and problem-solving skills". (R1)

\subsection{The Exemplary Practices of Soft Skills}

The exemplary practices of soft skills associated with business activities are encouraged to integrate through case study during the entrepreneurship training program. This can be one of the methods to train future entrepreneurs with sufficient soft skills to enhance their entrepreneurial capacity. Besides, the results show that exemplary practices of these soft skills utilizing training needs assessment would help entrepreneurs to get more involvements in business activities and improvement in their capacity of daily works. The following are the verbatim results from the informants:

"For me as the practitioner of this example of the soft skill that entrepreneurs should have somehow it could be done through a case study from video or it could be a case study that is designed for the student to understand what happens if they do not have these soft skills that would be limited them to be successful entrepreneurs". (R1)

\subsection{Soft Skills are Imparted through Designing of a Need-based Training Program}

There are three informants (R1, R3, and R5) indicated that soft skills should be imparted through designing a needbased training program to enhance entrepreneurial capacity. By doing so, the soft skills development training program can provide more efficacy and more knowledge value to the trainees. The results show that the imparted through design based on a training program utilizing group sharing has a positive impact on the trainer as well. The following are the verbatim results from the informants:

"Yes, I prefer the soft skills which were imparted through design-based training program because this kind of program can provide more efficacy and impact to the trainer as well so they can develop their mindset and its development as well". (R1)

"For the soft skills that impart through the design of the training program, it could be somehow like key criteria. For example, the literacy program to intend as I mean the subject purpose of the student so we can select which kind of item is suitable through designing of the program". (R3)

"I think like we should have more sharing like we can set up as group sharing for the experience for what is the best way, we set for the topic like we usually take, for example, communication because if we have well communication we can connect each other and for the stakeholder to improve the business". (R5) 


\subsection{Proposed the Methodology of Conducting Soft Skills Development Training Program}

The results revealed that three informants (R2, R3, and R4) proposed a methodology of conducting soft skills development training program. They emphasized that trainees must share their experiences and course content with the trainer so that they can obtain more knowledge and understanding of soft skills. Moreover, course contents need to focus on critical thinking and problem-solving skills and use the assessment tool to measure the soft skills developmental process. The following results reveal that the proposed methodology encompassing power point presentation, experienced trainer, and effective assessment tool to measure soft skills developmental process. The following are the verbatim results from the informants:

"The methodology should design the program that will not take a long time but need to make sure there is sufficient time for trainees to go through with the guest speaker about the course contents. I suggested doing the power point presentation. I feel like a good methodology is to have the guest speaker who has more experiences and willing to share his experiences". (R2)

"Currently, I think the best methodology is the soft skills development training program should be somehow based on learning or it could be team-based exercise or team-based group work because, in the current society, entrepreneurs cannot work on their own to achieve their goals. So, it could be somehow let trainees work together and then they solve the problem together to enhance their leadership skills and also communication skill". (R3)

"I think, we should evaluate the current training approach, modify and improve it to be effective pedagogical practices for soft skills development." (R4)

\section{Discussion}

The ultimate results revealed that there is a growing body of research suggesting that soft skills, namely leadership, communication, and critical thinking and problem-solving skills are associated with entrepreneurial capacity and success are malleable and can be trained. This is coupled with the current technological advancements that have changed the skills demanded in the business operations. When the demand for the skills and knowledge form deviations in the entrepreneurship, the higher education sector should encounter respectively to enhance their graduates' entrepreneurial capacity hence ensure innovation in the economy. As a result, the higher education institutions must respond by adjusting the content, the curriculum design, and the learning environments to fit the current and future entrepreneurial capacity requirements. Hence, the results further corresponding to the past researchers such as Tang et al. (2015a), Tang et al. (2015b), Tang (2019a), and Tang (2019b).

In conclusion, this study has successfully identified the importance of soft skills to enhance entrepreneurial capability. The literature review made based on the methodology used allowed researchers to further develop the soft skills development training program as the following phase of this study. The development of soft skills is critical to improving entrepreneurial capability where entrepreneurship is something natural becoming an integral part of our evolution and a new model of economy particular to Cambodia.

\section{Acknowledgments}

The authors gratefully acknowledge the use of service and facilities of the Faculty of Education, Khon Kaen University, Khon Kaen 40002, Thailand. The contents of this manuscript are derived from the first author's doctoral dissertation thus fulfilling the Ph.D. requirement of Khon Kaen University.

\section{References}

Asia Forward. (July 12, 2018). Successful entrepreneurs in Cambodia. Retrieved from https://www.forwardasia.com/stories/entrepreneurs/successful-entrepreneurs-in-cambodia/

Boyce, C., \& Neale, P. (2006). Conducting in-depth interviews: A guide for designing and conducting in-depth interviews for evaluation input. Pathfinder International Tool Series- Monitoring and Evaluation -2. Retrieved from http://www.pathfind.org/site/DocServer/m_e_tool_series_indepth_interviews.pdf?docID=6301

Castillo-Montoya, M. (2016). Preparing for interview research: The Interview Protocol Refinement Framework. The Qualitative Report, 21(5), 811-831. Retrieved from https://nsuworks.nova.edu/tqr/vol21/iss5/2

Chamorro-Premuzic, T., Arteche, A., Bremner, A. J., Greven, C., \& Furnham, A. (2010). Soft skills in higher education: Importance and improvement ratings as a function of individual differences and academic performance. Educational Psychology, 30(2), 221-241. https://doi.org/10.1080/01443410903560278

Groh, et al. (2016). The impact of soft skills training on female youth employment evidence from an RCT in Jordan. IZA Journal of Labor \& Development. https://doi.org/10.1186/s40175-016-0055-9 
Harvey, L. (2000). New realities: The relationship between higher education and employment. Tertiary Education and Management, 6, 3-7. https://doi.org/10.1080/13583883.2000.9967007

Hodges, D., \& Burchell, N. (2003). Business graduate competencies: Employers' views on importance and performance. Asia Pacific Journal of Cooperative Education, 4(2), 16-22.

Holloway, I., \& Wheeler, S. (2002). Qualitative research in nursing. Oxford, England: Blackwell Science.

Holmes, B. (2014). Hone the top 5 soft skills every college student needs. Retrieved from https://www.usnews.com/

Jain, V. (2009). What are soft skills. Retrieved from http://schoolofeducators.com/2009/02/Importance-of-softskills-development-in-education/

Josẽ Sousa, M. \& Do Rosặrio Almeida, M. (2014). Entrepreneurial skills development. Recent Advances Economics, 135-139.

McMullen, J. S., \& Shepherd, D. A. (2006). Entrepreneurial action and the role of uncertainty in the theory of entrepreneur. Academy Management Review, 31(1), 132-152. https://doi.org/10.5465/amr.2006.19379628

Miller, D., \& Friesen, P. (1983). Strategy-making and environment: The third link. Strategic Management Journal, 4, 221-235. https://doi.org/10.1002/smj.4250040304

Pratt, D., \& Yongvanit, S. (2018). Motivation and challenge: Working for international nongovernmental organizations in Cambodia. Kasetsart Journal of Social Sciences, in press, 1-6. https://doi.org/10.1016/j.kjss.2018.03.001

Salleh, K. M., Sulaiman, N. L., \& Talib, K. N. (2010). Globalization's impact on soft skills demand in the Malaysian workforce and organizations: What makes graduates employable? Paper presented at the $1^{\text {st }}$ UPI International Conference on Technical and Vocational Education and Training. Retrieved from http://fptk.upi.edu/textconference/download/TVETConferenceProceedings?Papers_Theme2/06_khairol_mo hd_salleh.pdf

Tan, C. Y., \& Tang, K. N. (2015). A study on soft skill development among final year Diploma in Business Studies students. Malaysian Online Journal of Educational Management, 3(2), 32-50.

Tang, K. N. (2012). Leadership soft skills. Sociology Study, 2(4), 261-269.

Tang, K. N. (2018). The importance of soft skills acquisition by teachers in higher education institutions. Kasetsart Journal of Social Sciences, in press, 1-6. https://doi.org/10.1016/j.kjss.2018.01.002

Tang, K. N. (2019a). Beyond employability: Embedding soft skills in higher education. The Turkish Online Journal of Educational Technology, 18(2), 1-9.

Tang, K. N. (2019b). Innovate higher education to enhance graduate employability. Pertanika Journal of Social Sciences \& Humanities, 27(3), 1727-1738.

Tang, K. N., Mohamed, S. H., \& Somprach, K. (2015). Soft skills of leaders and school improvement in high performing schools. Procedia-Social and Behavioral Sciences, 191, 2127-2131. https://doi.org/10.1016/j.sbspro.2015.04.652

Tang, K. N., Tan, C. C., \& Vetriveilmany, U. D. (2015). Critical issues of soft skills development in teaching professional training: Educators' perspective. Procedia Social and Behavioral Sciences, 205, 123-133. https://doi.org/10.1016/j.sbspro.2015.09.039

Than, C. (2015). Cambodia inter-census economic survey. Phnom Penh, Cambodia: Ministry of Planning.

Webb, J. (1992). Understanding and designing marketing research. London, United Kingdom: The Dryden Press.

Yin, R. K. (2003). Case study research design and methods. Applied Social Research Series, Vol. 5. California, United States: Sage.

\section{Copyrights}

Copyright for this article is retained by the author(s), with first publication rights granted to the journal.

This is an open-access article distributed under the terms and conditions of the Creative Commons Attribution license (http://creativecommons.org/licenses/by/4.0/). 